\title{
Produção e caracterização de celulose pela Glucanoacetobacter hansenii em meio contendo glicose ou manitol
}

\author{
Production and characterization of cellulose \\ by Glucanoacetobacter hansenii in medium \\ containing glucose or mannitol
}

Grazielly Maria Didier de Vasconcelos ${ }^{1}$, Karina Carvalho de Souza ${ }^{2}$, Ivo Diego de Lima Silva ${ }^{3}$, Alicia Catarina Pereira Felix da Silva ${ }^{2}$, Glória Maria Vinhas ${ }^{3}$

\footnotetext{
${ }^{1}$ Laboratório de Materiais Poliméricos e Caracterização - LMPC - DEQ/CTG/UFPE, CEP: 2126-7287, Recife, PE, Brasil

${ }^{2}$ Laboratório de Microbiologia - DEQ/CTG/UFPE, CEP: 2126-3010, Recife, PE, Brasil.

${ }^{3}$ Laboratório de Bioprocessos - DEQ/CTG/UFPE - 2126-7287, Recife, PE, Brasil.

e-mail: grazielly.didier@gmail.com, karinacar_souza@hotmail.com, ivo.diego91@gmail.com, aliciacatarina@gmail.com, gmvinhas@yahoo.com.br
}

\begin{abstract}
RESUMO
A celulose, polissacarídeo de origem vegetal, é um biopolímero abundante encontrado na natureza e, portanto, de grande valia para a ciência dos materiais em aplicações na área médica, cosmética, refinaria e outros. Como alternativa à produção tradicional de celulose, tem-se a via microbiana, que resulta numa fibra de caráter nanométrico e com boas propriedades mecânicas. Dentre os diversos micro-organismos que produzem celulose bacteriana (CB), e que apresenta resultados satisfatórios destaca-se a bactéria estritamente aeróbica e Gram-negativa conhecida como Gluconacetobacter hansenii (ATCC - 23769). Esse biopolímero apresenta enorme potencial de aplicação devido às suas propriedades térmicas, mecânicas e biocompatibilidade. Muitas pesquisas estão sendo realizadas para otimizar os processos produtivos de CB, resultando em maiores conversões com um menor custo produtivo. $\mathrm{O}$ presente trabalho teve como objetivo, produzir as membranas de celulose bacteriana em meio de manitol (C-MM) ou Hestrin e Schramm (C-MH), e também caracterizá-las por meio de análises de espectroscopia de infravermelho (IV), termogravimétrica (TGA), e difração de raios X (DRX). Como principais resultados, as celuloses produzidas apresentaram imagens morfológicas similares, mas no meio de manitol apresentou maior rendimento (2,09 g.L $\left.\mathrm{L}^{-1}\right)$ na produção de CB, quando comparado ao Meio Hestrin e Schramm (HS) (1,15 g.L ${ }^{-1}$ ). Além disso, a celulose bacteriana produzida no meio de manitol apresentou maior cristalinidade (78\%) que a produzida no meio de Hestrin e Schramm (HS) (65\%). Através da análise de IV, foi possível confirmar os grupos funcionais existentes na celulose bacteriana sem a presença de quaisquer contaminantes oriundo do processo de produção. Já com relação a análise termogravimétrica, o polímero formado a partir do meio de manitol apresentou maior estabilidade térmica. Desta forma, os biofilmes produzidos nos diferentes meios apresentaram propriedades diferentes, revelando que as características poliméricas são modificadas em função do meio de crescimento bacteriano.
\end{abstract}

Palavras-chave: Celulose bacteriana, Glucanoacetobacter hansenii, Manitol, Glicose.

\section{ABSTRACT}

The cellulose, polysaccharide of vegetable origin, is an abundant biopolymer found in nature and, therefore, a valuable tool for the science of materials applications in the medical, cosmetic, refinery, and other areas. As an alternative to traditional cellulose production, we have the microbial path, which results in a nanometric fiber with good mechanical properties. Among the several microorganisms that produce bacterial cellulose $(\mathrm{BC})$, the one that presents very satisfactory results is the strictly aerobic and Gram-negative bacteria known as Gluconacetobacter hansenii (ATCC - 23769). This biopolymer presents enormous application potential 
due to its thermal, mechanical and biocompatibility properties. Many researches are being developed to optimize the productive processes of $\mathrm{BC}$, resulting in greater conversions with a lower production cost. This work aimed to produce the cellulose membranes obtained in mannitol (C-MM) or Hestrin and Schramm (HS) (C-MH) medium and to characterize them through infrared spectroscopy (IR), thermogravimetric (TGA) and $\mathrm{X}$-ray diffraction (XRD) analyses. The celluloses produced presented similar morphological images, but the mannitol medium had a higher yield $\left(2.09 \mathrm{~g} . \mathrm{L}^{-1}\right)$ in the BC production when compared to the Hestrin and Schramm medium (HS) $\left(1.15 \mathrm{~g}\right.$. $\left.\mathrm{L}^{-1}\right)$. In addition, the bacterial cellulose produced in medium containing mannitol presented higher crystallinity (78\%) than that produced in Hestrin e Schramm (HS) (65\%). Through the IR analysis, it was possible to confirm the functional groups present in the bacterial cellulose without any contaminants from the production process. Regarding the thermogravimetric analysis, the polymer formed from the mannitol medium presented higher thermal stability. Finally, the biofilms produced in the different medium had different properties, revealing that the polymeric characteristics change according to the bacterial growth medium.

Keywords: Bacterial cellulose, Glucanoacetobacter hansenii, Mannitol, Glucose.

\section{INTRODUÇÃO}

As microfibrilas da Celulose Bacteriana (CB), apresentam as unidades de celobiose dispostas em paralelo, conferindo a molécula de celulose uma orientação plana, além disso, são aproximadamente 100 vezes mais finas que as da celulose vegetal, tornando-a um material de alta porosidade com excelentes propriedades mecânicas. Outra característica desse biopolímero é sua elevada cristalinidade, alto grau de polimerização, alta força de tensão e grande capacidade de hidratação [1]. Ainda nesta comparação, esse biomaterial, não produz reações tóxicas ou imunológicas quando inserido ou em contato com tecidos vivos [2].

Dentre as diversas culturas que produzem $\mathrm{CB}$, a bactéria estritamente aeróbica e Gram-negativa conhecida como Gluconacetobacter hansenii merece destaque [3]. Dependendo do processamento da síntese, o polímero formado pode ter diferentes propriedades como cristalinidade, temperatura de degradação, módulo de elasticidade, entre outras [4]. Quando o processo se dá de forma estacionária, uma membrana espessa e gelatinosa de celulose acumula-se na superfície do meio de cultura. Já quando se tem condições de cultura agitada, a CB pode ser sintetizada na forma de uma suspensão fibrosa ou esferas [5]. A celulose bacteriana formada funciona como mecanismo de flotação para os micro-organismos que permanecem na interface ar/líquido para obter oxigênio mais facilmente [6].

Mesmo com enorme potencial de aplicação devido às suas características, a viabilidade produtiva e econômica da síntese por via microbiológica pode ser melhorada. Além disso, acredita-se que diferentes propriedades da $\mathrm{CB}$ estão associadas à fonte de carbono no meio de produção [7]. Frente a isso, torna-se importante otimizar os processos produtivos de $\mathrm{CB}$, resultando em maiores conversões e identificando as principais propriedades do biopolímero em função do meio de produção [8 e 9].

O presente trabalho possui como principal objetivo, produzir e avaliar as propriedades da celulose bacteriana, em cultivo estático, utilizando o Meio Hestrin e Schramm (HS) ou Meio de manitol, pela bactéria Gluconacetobacter hansenii ATCC - 23769.

\section{MATERIAIS E MÉTODOS}

\subsection{Micro-organismo}

O micro-organismo Gluconacetobacter hansenii utilizado para a realização dos experimentos é classificado como uma linhagem de referência ATCC-23769 (American Type Culture Collection, USA), que foi adquirido pela Coleção de Culturas Tropical - CCT da Fundação Tropical de Pesquisa Tecnologica Andre Tosello.

\subsection{Meio para conservação da cultura}

O meio de cultura utilizado para a conservação da bactéria foi o Hestrin e Schramm (HS) modificado [10]. O mesmo foi preparado com a seguinte composição: glicose $\left(\mathrm{C}_{6} \mathrm{H}_{12} \mathrm{O}_{6} 30\right.$ g.L.- $\left.{ }^{-1}\right)$, peptona $\left(5\right.$ g.L $\left.\mathrm{L}^{-1}\right)$, extrato de levedura (5 g.L $\left.\mathrm{L}^{-1}\right)$, fosfato dissódico $\left(\mathrm{Na}_{2} \mathrm{HPO}_{4} \cdot \mathrm{H}_{2} \mathrm{O} 5,1 \mathrm{~g} . \mathrm{L}^{-1}\right)$, ácido cítrico $\left(\mathrm{C}_{6} \mathrm{H}_{8} \mathrm{O}_{7} 1,15 \mathrm{~g} . \mathrm{L}^{-1}\right)$ e água. $\mathrm{O}$ $\mathrm{pH}$ do meio foi corrigido para o intervalo de 5 a 6 utilizando-se soluções de ácido cítrico $0,1 \mathrm{M}$ ou de hidróxido de sódio 0,1M. Por fim, os meios foram esterilizados em autoclave vertical (marca Prismatec e modelo CS), de 15 a 20 minutos a $121^{\circ} \mathrm{C}$ e 1 atm. 


\subsection{Preparação do inóculo}

Dois inóculos foram preparados em frascos de Erlenmeyer $(125 \mathrm{~mL})$, ambos contendo $50 \mathrm{~mL}$ de meio Hestrin e Schramm (HS) (glicose 30 g.L. $\mathrm{L}^{-1}$, peptona 5 g.L $\mathrm{L}^{-1}$, extrato de levedura $5 \mathrm{~g} . \mathrm{L}^{-1}$, fosfato dissódico $5,1 \mathrm{~g} . \mathrm{L}^{-1}$, ácido cítrico 1,15 g.L $\mathrm{L}^{-1}$ e água destilada) e meio de manitol (manitol $25 \mathrm{~g} . \mathrm{L}^{-1}$, peptona $3 \mathrm{~g} . \mathrm{L}^{-1}$, extrato de levedura 5 g.L $\mathrm{L}^{-1}$ e água destilada), respectivamente. Para cada meio, foram transferidas três alçadas de bactérias crescidas no meio de conservação e finalmente incubados por 3 dias a $30^{\circ} \mathrm{C}$.

\subsection{Produção dos filmes poliméricos}

Para a realização do estudo foram preparados $200 \mathrm{~mL}$ de meios manitol e Hestrin e Schramm (HS), que foram distribuídos em 4 Erlenmeyers, sendo dois para cada meio, com volume útil de $50 \mathrm{~mL}$. Os Erlenmeyers contendo os meios de cultura foram esterilizados em autoclave durante 15 min a $121^{\circ} \mathrm{C}$ e $1 \mathrm{~atm}$.

De cada inóculo, conforme descrição do item acima, foi transferido $10 \%$ (V/V) para cada um dos 4 Erlenmeyers, os quais foram incubados à $28{ }^{\circ} \mathrm{C}$ por um período de 14 dias. As coletas dos biofilmes formados foram realizadas por filtração, em papel de filtro faixa branca da marca Schleicher\&Schüll com $125 \mathrm{~mm}$ de diâmetro.

As membranas produzidas foram purificadas por um tratamento à quente em banho-maria à $80^{\circ} \mathrm{C}$ por 20 minutos com a solução de hidróxido de sódio 0,1M. Após o tratamento, as películas de CB foram lavadas com água destilada e armazenadas em placas de Petri abertas e dispostas em freezer à $-2{ }^{\circ} \mathrm{C}$ por 72 horas. Para estabilização da umidade, os polímeros foram postos em dessecador para perda máxima de água e acompanhamento da massa por pesagem para possibilitar análise de produtividade (Equação 1) entre os meios estudados.

$$
\text { Produtividade }\left(\text { g. } \mathrm{I}^{-1}\right)=\frac{\text { Massa saca da memhrana (g) }}{\text { Mejo do cultura (L) }}
$$

\subsection{Difratometria de Raios X (DRX)}

Para identificação das fases cristalinas da membrana de celulose, utilizou-se a técnica de difratometria de raios X. Os filmes foram analisados por um difratômetro Rigaku com tubo de cobre em $40 \mathrm{kV}$ e $20 \mathrm{~mA}$, escala de $2 \theta$ com intervalo entre $5^{\circ}$ e $55^{\circ}$ com velocidade de varredura de $0,5^{\circ} / \mathrm{min}$. Na Equação 1 , método de cálculo foi desenvolvido por SEGAL et al. [11] que se baseia na diferença da intensidade entre os picos de maior e menor intensidade, foi utilizado para determinação do percentual de celulose cristalina (\% C).

$$
\text { Cristalinidade }(\%)=\frac{\left(I_{c}-I_{m m}\right)}{I_{c}} \times 100
$$

Com $\mathrm{I}_{\mathrm{c}}$ igual à intensidade máxima da difração de rede, e $\mathrm{I}_{\mathrm{am}}$ sendo a intensidade do pico em $2 \theta=18^{\circ}$, que representa a parte amorfa da celulose. A intensidade dos picos foi medida como o valor máximo obtido para o pico levando em conta uma linha de base [11].

\subsection{Espectroscopia de Infravermelho (IV)}

A espectroscopia de infravermelho foi utilizada para caracterizar a estrutura química da membrana de celulose bacteriana. Esta análise foi realizada no equipamento Spectrum 400 FT-IR/FT-NIR Spectrometer da marca Perkin Elmer com o acessório UATR Spectrum 100. As amostras analisadas correspondiam as membranas coletadas com 14 dias de incubação, obtendo-se uma média de três espectros por amostra, com a finalidade de realizar a análise de componentes principais que foi desenvolvida no software The Unscrambler utilizando os dados brutos de cada espectro obtido.

\subsection{Análise Termogravimétrica (TGA)}

A temperatura característica de degradação $\left(T_{d}\right)$ das membranas de celulose foi definida através de análise termogravimétrica realizada na faixa de temperatura de $30{ }^{\circ} \mathrm{C}$ a $600{ }^{\circ} \mathrm{C}$, com uma taxa de aquecimento de $30{ }^{\circ} \mathrm{C}$ por minuto. A análise foi realizada no equipamento Simultaneos Thermal Analyzer - STA $6000 \mathrm{da}$ marca Perkin Elmer, a partir de aproximadamente 20mg de amostra. 


\subsection{Microscopia Óptica}

Para a obtenção de mais detalhes morfológicos da superfície da membrana celulósica utilizou-se um microscópio LEICA DM750, a visualização foi feita com lentes objetivas para a ampliação de 10x da imagem original.

\section{RESULTADOS}

\subsection{Produção e caracterização morfológica dos filmes poliméricos}

As bactérias acéticas produtoras de celulose bacterianas, quando utilizam o manitol como fonte de carbono, metabolicamente converte esse carboidrato em frutose para depois direcionar para produção de celulose. Enquanto a glicose é transportada através da membrana celular e incorporada à biossíntese da celulose [12]. Esse fato pode estar associado ao maior rendimento obtido pelo meio de manitol na produção de CB (2,09 g.L $\left.\mathrm{L}^{-1}\right)$, quando comparado ao meio Hestrin e Schramm (HS) $\left(1,15\right.$ g.L $\left.\mathrm{L}^{-1}\right)$.

Na Figura 1 estão apresentadas imagens macrográficas e de microscopias ópticas das películas de celulose bacteriana (CB), após o processo de purificação e secagem. Ambas as celuloses produzidas, C-MM (Figura 1A e 1B) e C-MH (Figura 1C e 1D) apresentaram morfologias similares, caracterizando filmes homogêneos (Figura 1A e 1C), como também é possível visualizar pela microscopia óptica as rugosidades oriundas do processo de secagem (Figura 1B e 1D).

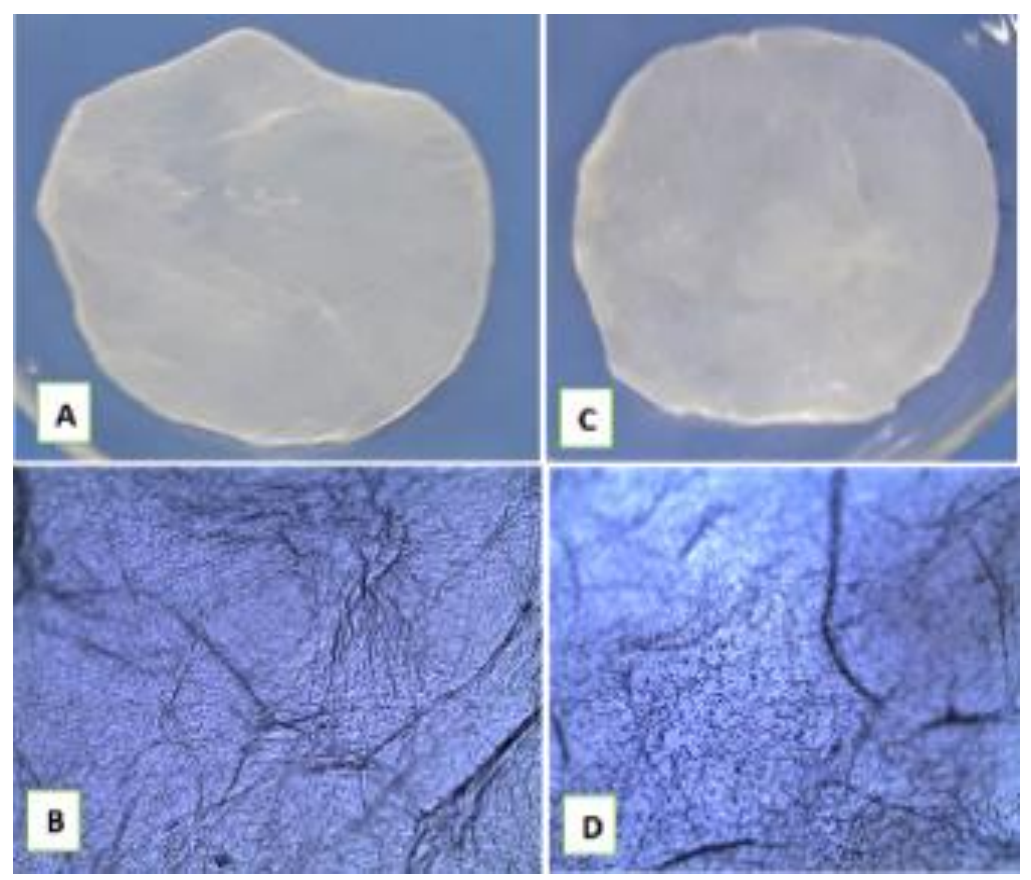

Figura 1: Celulose bacteriana C-MM (A e B) e C-MH (C e D). As microscopias ópticas com ampliação de 10x.

\subsection{Difração de Raios-X (DRX)}

A Figura 2 mostra os difratogramas de raios $\mathrm{X}$ referentes às biomembranas estudadas. 


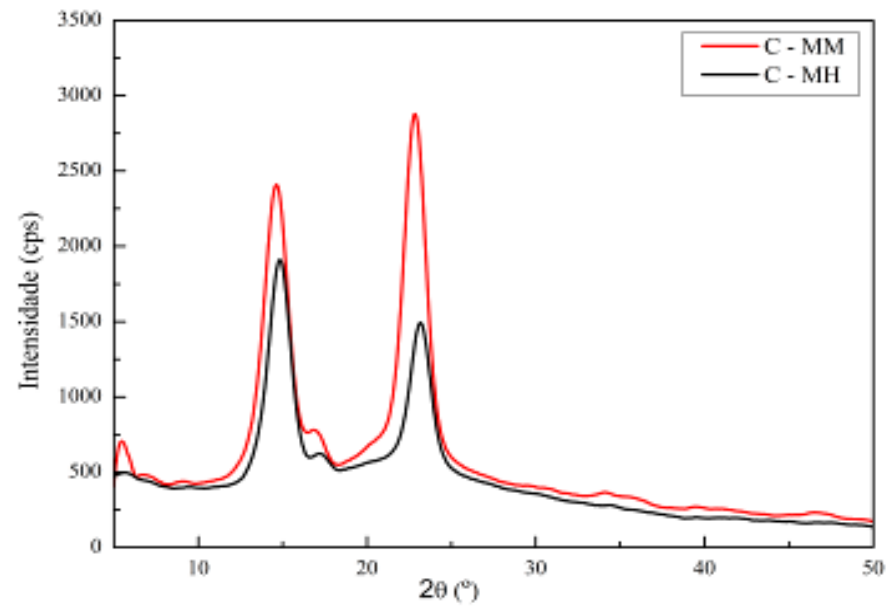

Figura 2: Difratogramas das CB obtidas nos diferentes meios.

A partir do comportamento ilustrado acima, pode-se observar que ambas as membranas apresentaram picos característicos de celulose bacteriana que são os picos de difração $2 \theta \mathrm{em} 14,7^{\circ}, 14,9^{\circ}, 22,9^{\circ}$ e $23,2^{\circ}$, os quais são normalmente atribuídos à distância existente entre os planos cristalográficos típicos das fases $\mathrm{I}_{\alpha}$ e $\mathrm{I}_{\beta}$ da estrutura cristalina [13 e 14].

Como a celulose não é um material completamente cristalino (semi-cristalino), os difratogramas apresentam picos largos e como os biopolímeros foram produzidos a partir de meios diferentes, percebem-se diferenças entre as intensidades e configurações desses picos. Mas, ambas as celuloses podem ser caracterizadas por picos que as classificam em tipos I e II, cujas diferenças estão descritas na Tabela 1 [6 e $15]$.

Tabela 1: Picos característicos de celulose dos tipos I e II [6 e 15]

\begin{tabular}{c|c|c}
\hline Celulose & Região amorfa & Região cristalina \\
\hline Tipo I & $18^{\circ} \leq 2 \theta \leq 19^{\circ}$ & $22^{\circ} \leq 2 \theta \leq 23^{\circ}$ \\
\hline Tipo II & $13^{\circ} \leq 2 \theta \leq 15^{\circ}$ & $18^{\circ} \leq 2 \theta \leq 22^{\circ}$ \\
\hline
\end{tabular}

O grau de cristalinidade para as celuloses foi de $65 \%$ e $78 \%$ para a C-MH e C-MM respectivamente. A literatura relata que o índice de cristalinidade da CB encontra-se ente 60 e 95\%, colocando, portanto, os resultados das análises das membranas formadas, de ambos os meios, dentro dos limites de alta cristalinidade, como esperado [16]. Outros autores como Mikkelsen et al., [12] também encontraram valores de cristalinidade $(90 \pm 5 \%)$ superiores para $\mathrm{CB}$ cultivadas em meio contendo manitol, quando comparado a cristalinidade do meio contendo glicose como fonte de carbono $(80 \pm 5 \%)$. Comparando esses resultados com os obtidos nesse trabalho, a Bactéria Gluconacetobacter hansenii produziu uma CB com percentuais de cristalinidade inferiores, mantendo a mais alta cristalinidade para o meio contendo manitol. A composição do meio contendo o açúcar poliol (manitol) atuou não somente como fonte de energia, mas também como precursor para a biossíntese da $\mathrm{CB}$ com percentual maior organização das cadeias, originado uma biomembrana mais cristalina.

\subsection{Espectroscopia de Infravermelho (IV)}

Os espectros de infravermelho foram realizados com a finalidade de determinar os picos característicos das bandas de celulose e verificar a possível ocorrência de novos picos inerentes a alguma interação entre a celulose e os componentes do meio, principalmente a presença de fonte de carbono residual. Os espectros dos biofilmes estão apresentados na Figura 3, e mostram semelhanças entre as celuloses produzidas nos dois meios, além da confirmação dos grupos vibracionais pertencentes a estrutura da celulose bacteriana em ambos os espectros. 


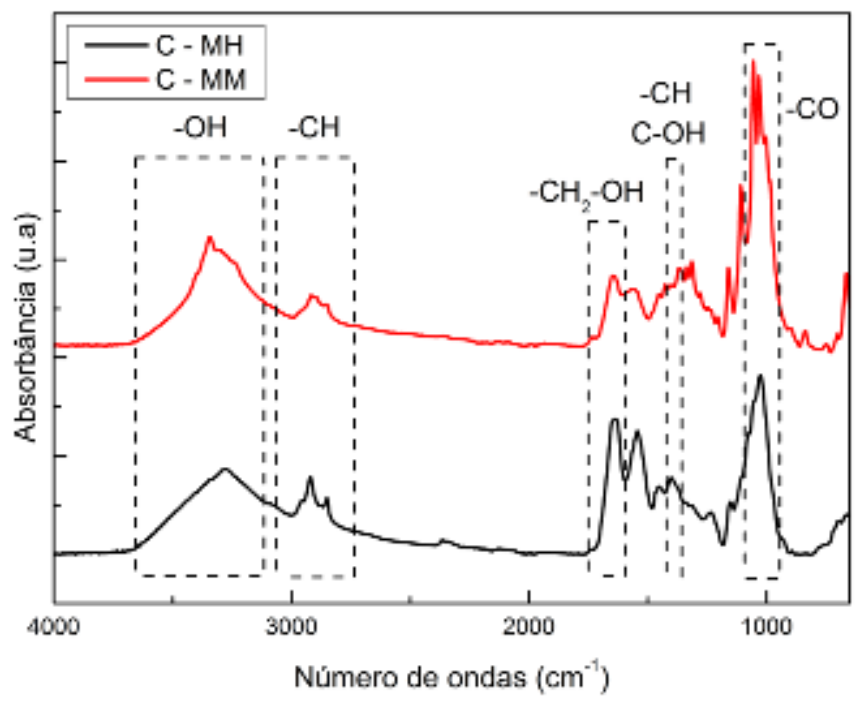

Figura 3: Espectros de infravermelho das CB obtidas nos meios Hestrin e Schramm (C-MH) e manitol (C-MM).

Na literatura são encontradas caracterizações das estruturas químicas por infravermelho das celuloses bacterianas, entre os estudos podemos destacar o de Saska e seus colaboradores que produziram membranas de celulose bacteriana utilizando a linhagem Gluconacetobacter xylinus ATCC-23769 em meio Hestrin e Schramm (HS) modificado e glicose como principal fonte de carbono. A produção de CB foi desenvolvida de forma estática por 120 horas a $28^{\circ} \mathrm{C}$ [14]. Na Tabela 2, estão dispostas as principais bandas características da celulose bacteriana, com seus respectivos grupos funcionais que foram encontrados nas celuloses produzidas nos dois meios (C-MH e C-MM). Essas bandas vibracionais foram também identificadas nos trabalhos de Saska et al., Gea et al. e Pecoraro et al., que produziram essas membranas de celulose, caracterizando grupos funcionais do carboidrato, como unidade monomérica do polímero de celulose, similares às encontradas nesse estudo [14, 17 e 18$]$.

Tabela 2: Frequências típicas de absorção no Infravermelho da celulose produzida para a CB [14, 17 e 18].

\begin{tabular}{c|c|c|c}
\hline \multirow{2}{*}{$\begin{array}{c}\text { Faixa de } \\
\text { número de } \\
\text { onda }\left(\mathbf{c m}^{-1}\right)\end{array}$} & Característica e grupo responsável & \multicolumn{2}{|c}{$\begin{array}{c}\text { Número de onda } \\
\text { encontrada na Celulose } \\
\text { produzida }\end{array}$} \\
\cline { 3 - 4 } & & C-MH & C-MM \\
\hline $3400-3200$ & $\begin{array}{c}\text { Banda forte e larga, resultante de associações } \\
\text { poliméricas do estiramento do grupo } \\
\text { Hidroxila }(\mathrm{OH})\end{array}$ & 3286 & 3348 \\
\hline $2960-2850$ & $\begin{array}{c}\text { Estiramento de CH de alcanos e estiramento } \\
\text { assimétrico CH }\end{array}$ & 2921 & 2912 \\
\hline $1680-1620$ & Deformação de CH ${ }_{2}-\mathrm{OH}$ & 1639 & 1648 \\
\hline $1430-1330$ & Deformação C-OH e CH & 1399 & 1367 \\
\hline $1320-1030$ & Deformação C-O & 1033 & 1044 \\
\hline $1200-1000$ & Estiramento C-O (-C-O-H) & 1034 & 1051 \\
\hline $1160-1146$ & Estiramento (C-O-C); deformação CH & 1154 & 1158 \\
\hline $700-400$ & Deformação fora do plano -OH & 669 & 607 \\
\hline & & & \\
\hline
\end{tabular}

Desta forma, por meio da análise de IV, foi possível confirmar os grupos funcionais existentes na celulose bacteriana, bem como identificar que o processo de purificação foi eficiente, não deixando componentes residuais do meio de produção ou presença de outros metabólitos na matriz polimérica [17 e $18]$. 


\subsection{Análise dos Componentes Principais (PCA)}

A análise de componentes principais foi utilizada com o intuito de observar se há alguma diferença química vibracional das estruturas de CB produzidas pelos meios Hestrin e Schramm (HS) e manitol. A Figura 4 mostra o gráfico da análise de componentes principais dos espectros de Infravermelho das celuloses bacterianas produzidos nos dois meios de produção em estudo. Observa-se que as componentes PC1, PC2 e PC3 explicaram, respectivamente, $80 \%, 15 \%$ e 3\% das informações referentes as diferenças das vibrações estruturais da celulose. Desta forma, pode-se constatar que há características químicas vibracionais distintas para os biofilmes C-MH e C-MM. As celuloses bacterianas $\mathrm{C}-\mathrm{MH}$ encontram-se agrupadas, mostrando estruturas semelhantes entre si. O mesmo pode ser observado para as C-MM, que estruturalmente são semelhantes. Logo, esse agrupamento revela a similaridade vibracional de todas as membranas produzidas pelo meio de manitol, como também todas as vibrações semelhantes das membranas produzidas pelo meio Hestrin e Schramm (HS).

Scores

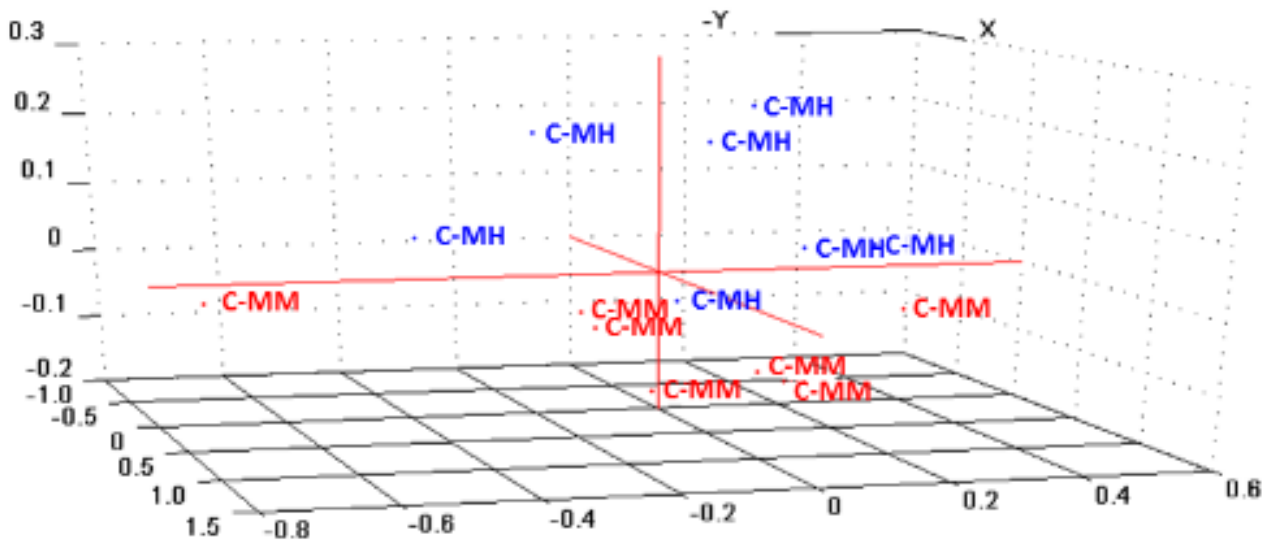

PCA - celulose, X-expl: $80 \%, 15 \%, 3 \%$

Figura 4: Análise dos componentes principais das amostras de CB para o meio de Hestrin e Schramm e manitol.

\subsection{Análise Termogravimétrica (TGA)}

Analisando o termograma das celuloses bacterianas (Figura 5a e 5b) e a Tabela 3, pode-se observar uma diminuição da perda de umidade em temperaturas próximas a $100{ }^{\circ} \mathrm{C}$ para as $\mathrm{C}-\mathrm{MH}$ e C-MM. Nessa temperatura, as membranas produzidas nos meios C-MH e C-MM tiveram perdas de aproximadamente 7,4\% e de $4,8 \%$ de água, respectivamente. O fato de a perda de água ter sido menos acentuada na C-MM pode ser explicado pela dificuldade da eliminação da água que estava nos domínios cristalinos da estrutura durante a etapa da secagem da membrana, uma vez que esse biopolímero apresentou um percentual de cristalinidade maior. 

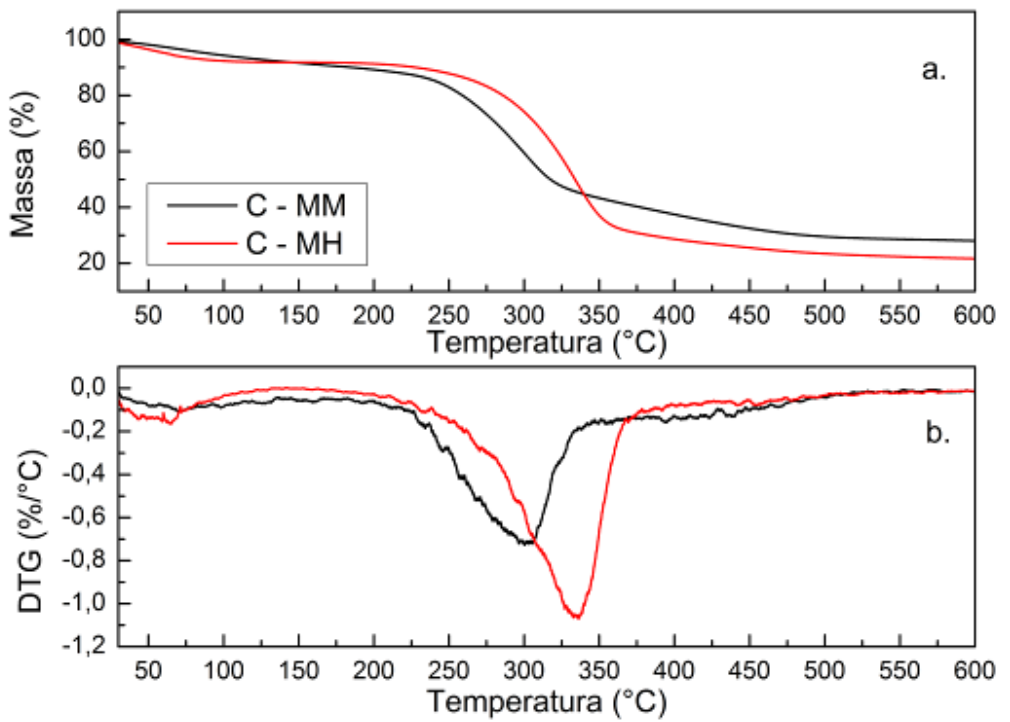

Figura 5: a. Termograma da TGA e b. curvas DTG das CB para cada celulose produzida.

À medida que a temperatura aumenta, a massa foi diminuindo, entrando na faixa de degradação da celulose bacteriana, caracterizada por uma diminuição em torno de $64 \%$ da massa da C-MH e $50 \%$ da C-MM, respectivamente. Acima de $\pm 350{ }^{\circ} \mathrm{C}$ pode-se observar um novo comportamento térmico, indicativo da degradação termo-oxidativa que estabilizou a massa da celulose em torno de $33 \%$ e $41 \%$ da inicial para as amostras C-MH e C-MM, respectivamente.

Tabela 3: Dados da temperatura e perda de massa das C-MM e C-MH.

\begin{tabular}{c|c|c|c}
\hline \multicolumn{4}{c}{ Análise Termogravimétrica - TGA } \\
\hline \multicolumn{4}{c}{ Perda de umidade (até $\left.100{ }^{\circ} \mathrm{C}\right)$} \\
\hline Amostra & $\mathrm{M}_{\text {inicial }}(\mathrm{mg})$ & $\mathrm{M}_{\text {final }}(\mathrm{mg})$ & Perda $\%$ \\
\hline C-MM & 15,46169 & 14,71292 & 4,842751 \\
\hline C-MH & 12,74588 & 11,80688 & 7,367084 \\
\hline \multicolumn{4}{c}{ Faixa degradativa $\left(\right.$ até $\left.+/-350{ }^{\circ} \mathrm{C}\right)$} \\
\hline Amostra & $\mathrm{M}_{\text {inicial }}(\mathrm{mg})$ & $\mathrm{M}_{\text {final }}(\mathrm{mg})$ & Perda $\%$ \\
\hline C-MM & 14,71292 & 7,314253 & 50,28688 \\
\hline C-MH & 11,80688 & 4,141081 & 64,92654 \\
\hline Amostra & Degradação termo-oxidativa $\left(>350{ }^{\circ} \mathrm{C}\right)$ \\
\hline C-MM & $\mathrm{M}_{\text {inicial }}(\mathrm{mg})$ & $\mathrm{M}_{\text {final }}(\mathrm{mg})$ & Perda $\%$ \\
\hline C-MH & 7,314253 & 4,311073 & 41,05929 \\
\hline
\end{tabular}

Estudos que avaliam a estabilidade térmica da CB por termogravimetria trazem perfis de degradação semelhantes aos encontrados experimentalmente neste trabalho [13 e 17]. De acordo com as curvas e dados referentes as temperaturas $\left(\mathrm{T}_{\text {onset }}\right.$ e/ou $\mathrm{T}_{\max }$ ) (Figura 5 e Tabela 4), existem dois eventos principais, o primeiro correspondente à perda de massa pela desidratação da película $\left(100{ }^{\circ} \mathrm{C}\right)$ e o outro refere-se às degradações térmicas e oxidativa na faixa de 250 a $400{ }^{\circ} \mathrm{C}$. Entretanto, a membrana $\mathrm{C}-\mathrm{MH}$ apresentou um início de degradação em $261,5^{\circ} \mathrm{C}$ e temperatura máxima de degradação de $335{ }^{\circ} \mathrm{C}$, conferindo maior estabilidade térmica ao polímero. Os resultados obtidos também mostraram que a C-MM apresentou perfil de degradação diferente, com temperatura inicial de degradação e temperatura máxima de degradação menores que a membrana C-MH. A temperatura máxima de decomposição é um critério de estabilidade térmica e tais comportamentos são afetados por alguns parâmetros, como estrutura molecular, cristalinidade e orientação das fibras [19 e 20]. 
Tabela 4: Dados das temperaturas inicias $\left(\mathrm{T}_{\text {onset }}\right)$, temperaturas finais $\left(\mathrm{T}_{\text {ofset }}\right)$ e Temperaturas máximas de degradação $\left(\mathrm{T}_{\text {máx }}\right)$ das C-MH e C-MM.

\begin{tabular}{cccc|cccc}
\hline & \multicolumn{3}{c|}{$\mathbf{1}^{\circ}$ Estágio } & \multicolumn{3}{c}{ 20 Estágio } \\
\hline Amostras & $\mathbf{T}_{\text {onset }}$ & $\mathbf{T}_{\text {ofset }}$ & $\mathbf{T}_{\text {máx }}$ & $\mathbf{T}_{\text {onset }}$ & $\mathbf{T}_{\text {ofset }}$ & $\mathbf{T}_{\text {máx }}$ & Residual \\
& $\left.{ }^{\circ} \mathbf{C}\right)$ & $\left({ }^{\circ} \mathbf{C}\right)$ & $\left({ }^{\circ} \mathbf{C}\right)$ & $\left({ }^{\circ} \mathbf{C}\right)$ & $\left({ }^{\circ} \mathbf{C}\right)$ & $\left({ }^{\circ} \mathbf{C}\right)$ & $(\%)$ \\
\hline C-MH & 30,0 & 91,5 & 56,5 & 261,5 & 400,0 & 335,2 & 21,5 \\
C-MM & 30,0 & 112,5 & 66,6 & 245,0 & 327,3 & 300,0 & 27,9 \\
\hline
\end{tabular}

Em Resumo, a análise térmica confirma o que foi visto pela PCA e pelo DRX, que as celuloses bacterianas apresentaram propriedades térmicas, físicas e químicas diferentes, em função do tipo de meio que foram produzidas.

\section{CONCLUSÕES}

O presente trabalho possibilitou a avaliação da produção de celulose bacteriana, um material polimérico, biocompatível e biodegradável, a partir de dois meios de cultura estudados (Hestrin e Schramm (HS) e manitol), cujas respectivas fontes de carbono são glicose e manitol. A caracterização das membranas baseouse em análises de difração de raios X, infravermelho e análise termogravimétrica que possibilitaram constatar que a bactéria Gluconacetobacter hansenii ATCC - 23769 é capaz de produzir nanofibras de celulose com propriedades diferentes em função da mudança na fonte de carbono. Desta forma, o meio contendo o manitol, como principal fonte de carbono resultou num polímero com maior percentual de cristalinidade e maior estabilidade térmica. As análises de infravermelho e o PCA permitiram concluir a existência de grupos funcionais pertencentes à estrutura química da biomembrana, bem como identificar diferenças entre os filmes de $\mathrm{CB}$ provenientes de cada meio de cultura.

\section{BIBLIOGRAFIA}

[1] YOSHINO, A., TABUCHI M., UO, M., TATSUMI, H., et al., "Applicability of bacterial cellulose as an alternative to paper point in endodontic treatment”, Acta Biomaterialia, v. 9, n. 4, pp. 6116-6122, 2013.

[2] CZAJA, W., KRYSTYNOWICZ, A., KAWECKI, M., et al., "Biomedical Applications of Microbial Cellulose in Burn Wound Recovery", Springer, pp. 307-321, 2007.

[3] LYER, P.R., GEIB, S.M., CATCHMARK, J., KAO, T., TIEN, M. Genome sequence of a celluloseproducing bacterium, Gluconacetobacter hansenii ATCC 23769. J. of Bacteriol., v. 192 (16), pp. 4256-4257, 2010.

[4] GALAS, E., KRYSTYNOWICZ, A., TARABASZ-SZYMANSKA, L., et al., "Optimization of bacterial cellulose using multivariable linear regression analysis”, Acta Biotechnol, v. 19, pp. 251-260, 1999.

[5] KRYSTYNOWICZ, A., CZAJA, W., JEZIERSKA, A.W., et al., "Factors affecting the yield and properties of bacterial cellulose", J. Ind. Microbiol. Biotechnol, v. 29, n. 4, pp. 189-195, 2002.

[6] DONINI, I.A.N., SALVI, D.T.B., FUKUMOTO, F.K., et al., "Biossítese e recentes avanços na produção de celulose bacteriana", Eclet, Quím v. 35, n. 4, pp. 165-178, 2010.

[7] COSTA, A.F.S., ALMEIDA, F.C.G., VINHAS, G.M., et al., "Production of bacterial cellulose by Glucanoacetobacter hansenii using corn steel liquoe as nutriente sources", Frontiers in Microbiology, v. 8, pp. 2027, 2017.

[8] KESHK, S.M.S.S., SAMESHIMA, K., "Evaluation of different carbon sources for bacterial cellulose production", African Journal of Biotechnology, v. 6, pp. 478-482, 2005

[9] KESHK, S., SAMESHIMA, K., "The utilization of sugar cane molasses with/without the presence of lignosulfonate for the production of bacterial cellulose", Biotechnological Procucts and Process Engineering, pp. 291-296, 2006.

[10] HESTRIN, S., SCHARAM, M. "Synthesis of cellulose by Acetobacter xylinum. 2. Preparation of freeze-dried cells capable of polymerizing glucose to celulose", Biochemical Journal, v.58, n. 2, pp. 345-352, Out. 1957. 
[11] SEGAL, L., CREELY, J.J., MARTIN, A.E., et al.,An empirical method for estimating the degree of crystallinity of native cellulose using the X-ray diffractometer. Textile Research Journal, v. 29, n. 10, pp. 786-794, 1959.

[12] MIKKELSEN, D., FLANAGAN, B.M., DYKES, G.A., et al.,Influence of different carbon sources on bacterial cellulose production by Glucanoacetobacter xylinus strain ATCC 53524, Journal of Applied Microbiology, v. 107, n. 2, pp, 576-583, 2009.

[13] VAZQUEZ, A., FOREST, M.L., CERRUTI, P., et al., "Bacterial Cellulose from Simple and Low Cost Production Media by Gluconacetobacter xylinus“, Journal Polymer Environment. v. 21, pp. 545-554, 2013.

[14] SASKA, S.; TEIXEIRA, L.N.; OLIVEIRA, P.T.; et al., Bacterial cellulose-collagen nanocomposite for bone tissue engineering, Journal of Materials Chemistry, v. 22, n. 41, pp. 22102-22112, 2012.

[15] CHAWLA, P.R., BAJAJ, I.B., SURVASE, S.A., et al., "Microbial Cellulose: Fermentative Production and Applications", Food Technol. Biotechnol, v. 4, pp. 107-124, 2009.

[16] TROVATTI, E., SERAFIM, L.S., FREIRE, C.S.R., et al.,Gluconacetobacter sacchari: An efficient bacterial cellulose cell-factory, Carbohydr. Polym., v. 86, n. 3, pp. 1417-1420, 2011.

[17] GEA, S., REYNLDS, T.C., ROOHPOUR, N., et al., "Investigation into the structural, morphological, mechanical and thermal behavior of bacterial cellulose after a two-step purification process", Bioresource Technology, v. 102, pp. 9105-9110, 2011.

[18] PECORARO E., MANZANI, D., MESSADDEQ, Y., et al., "Bacterial Cellulose from Gluconacetobacter xilinus: Preparation, Properties and Applications”, In: LTDA. Monomers, Polymers and Composites from Renewable Resources, Elsevier, v. único, cap. 17, pp. 560, 2008.

[19] BARUD, H.S., RIBEIRO, C.A., CRESPI, M.S., et al., Thermal characterization of bacterial cellulosephosphatecomposite membranes, Journal of Thermal Analysis and Calorimetry, v. 87, n. 3, pp. 815-818, 2007.

[20] MOHAMMADKASEMI, F., AZIN, M. ASHORI, A., Production of bacterial cellulose using different carbon sources and culture media, Carbohydrate Polymers, v. 117, pp. 518-523, 2015.

\section{ORCID}

Grazielly Maria Didier de Vasconcelos

Karina Carvalho de Souza

https://orcid.org/0000-0003-0156-920X

Ivo Diego de Lima Silva

https://orcid.org/0000-0002-9902-7566

Alicia Catarina Pereira Felix da Silva

https://orcid.org/0000-0001-7441-2305

Glória Maria Vinhas

https://orcid.org/0000-0001-5073-609X 